\title{
Qualidade fisiológica de sementes de feijão carioca armazenadas em diferentes ambientes
}

\author{
Claudemir Zucareli ${ }^{1}$, Cristian R. Brzezinski ${ }^{1}$, Julia Abati ${ }^{1}$, Flávia Werner ${ }^{1}$, \\ Edison U. Ramos Júnior ${ }^{2} \&$ João Nakagawa ${ }^{3}$ \\ ${ }^{1}$ Programa de Pós-Graduação em Agronomia/Centro de Ciências Agrárias/Universidade Estadual de Londrina. Londrina, PR. E-mail: claudemircca@uel.br; \\ cristian_brzezinski@yahoo.com.br(Autor correspondente); juliaabati@yahoo.com.br; fla_werner@hotmail.com \\ ${ }^{2}$ Embrapa Soja. Sinop, MT. Brasil. E-mail: edisonramos@embrapa.br \\ ${ }^{3}$ Departamento de Produção Vegetal/Universidade Estadual Paulista “Júlio de Mesquita Filho”. Botucatu, SP. E-mail: secdamv@fc.unesp.br
}

\author{
Palavras-chave: \\ Phaseolus vulgaris L. \\ germinação \\ vigor \\ câmara seca \\ ambiente natural
}

\begin{abstract}
R E S U M O
Objetivou-se no trabalho avaliar a qualidade fisiológica de lotes de sementes de cultivares de feijão do tipo carioca ao longo do armazenamento em diferentes ambientes. O ensaio foi desenvolvido na Universidade Estadual de Londrina sob delineamento inteiramente casualizado, com quatro repetições, em esquema fatorial $3 \times 2 \times 4$ sendo três lotes de cultivares de feijão carioca (lote 1: Carioca Precoce, lote 2: IAC Carioca Tibatã e lote 3: IAC Carioca), dois ambientes de armazenamento (ambiente natural e câmara seca) e quatro épocas de armazenamento (0, 6, 12 e 18 meses). A qualidade das sementes foi avaliada pelos seguintes testes: teor de água, primeira contagem do teste de germinação, germinação, envelhecimento acelerado, condutividade elétrica e emergência de plântulas em campo. Os dados foram submetidos à análise de variância, comparação de médias pelo teste de Tukey a 0,05 de probabilidade e análise de regressão. Sementes de feijão do lote 1 (cultivar Carioca Precoce) e lote 3 (IAC Carioca) apresentam melhor qualidade fisiológica em relação ao lote 2 (IAC Carioca Tibatã). A qualidade fisiológica das sementes de feijão carioca é reduzida durante o armazenamento para todos os lotes, porém com taxas mais acentuadas sob condições não controladas de temperatura e umidade.
\end{abstract}

\section{Key words:}

Phaseolus vulgaris L. germination

vigor

dry chamber

natural environment

\section{Physiologic quality of carioca bean seeds stored in different environments}

\begin{abstract}
A B S T R A C T
The aim of the study was to evaluate the physiologic quality of lots of seeds of bean cultivars of carioca during storage in different environments. The study was conducted at the State University of Londrina, in a completely randomized design with four replications in a $3 \mathrm{x}$ $2 \times 4$ factorial design, with three lots of cultivars of common bean (lot 1: Carioca Prococe, lot 2: IAC Carioca Tibatã and lot 3: IAC Carioca), two storage environment (natural environment and dry chamber) and four storage times $(0,6,12$, and 18 months). Seed quality was evaluated by the following tests: water content, first count of germination, germination, accelerated aging, electrical conductivity and seedling emergence in the field test. Data were subjected to analysis of variance and comparisons of means by Tukey test at 0.05 probability and regression analysis. Seeds of beans of the lot 1 (Carioca Precoce) and lot 3 (IAC Carioca) had better physiologic quality against lot 2 (IAC Carioca Tibatã). The physiologic quality of seeds of beans is reduced during storage in all lots, but with steeper rates under uncontrolled temperature and humidity conditions.
\end{abstract}




\section{INTRODUÇÃo}

O feijão (Phaseolus vulgaris L.) é uma das culturas mais produzidas no Brasil e no mundo. A sua importância frente às principais explorações agrícolas se deve ao fator de segurança alimentar e nutricional baseado no alto conteúdo proteico dos seus grãos, o que o torna uma das principais fontes de proteína da dieta humana. Além de apresentar relevância cultural na culinária de diversos países e culturas (Toledo et al., 2009; Barbosa \& Gonzaga, 2012).

Diante deste cenário a obtenção de elevadas produtividades vem-se tornando essencial na prospecção desta cultura através da interação entre os fatores ambientais, técnicas de manejo, utilização de cultivares mais produtivas e o uso de sementes de alta qualidade (Binotti et al., 2008).

A semente se destaca por ser o insumo de maior significância no contexto de produtividade e para que esta seja considerada de alta qualidade deve apresentar características sanitárias, físicas, genéticas e fisiológicas adequadas (França Neto et al., 2010). Essas características são imprescindíveis para que as plantas possam expressar todo o seu potencial e elevar o rendimento final da cultura.

A preservação da qualidade das sementes durante o armazenamento, ou seja, da colheita até o momento da sua utilização, é um aspecto fundamental a ser considerado no seu processo produtivo (Oliveira et al., 1999). O armazenamento após a colheita deve ser conduzido de maneira a reduzir ao máximo as reações bioquímicas que provocam a perda da qualidade fisiológica das sementes, além de proporcionar condições desfavoráveis ao desenvolvimento de insetos e fungos, os quais contribuem para a redução desta qualidade (Villa \& Roa, 1979).

A qualidade das sementes não pode, portanto, ser melhorada pelo armazenamento mas sim preservada com o mínimo de deterioração possível, através do armazenamento adequado, visando manter o vigor e o poder germinativo pelo maior período possível (Popinigis, 1985; Goldfarb \& Queiroga, 2013). Caso a qualidade não seja mantida os esforços para o desenvolvimento do material e as técnicas culturais para a produção podem ser perdidos (Grisi \& Santos, 2007).

Dentre os fatores que determinam o potencial máximo de armazenamento das sementes se destacam a temperatura, a umidade e as características genéticas do produto armazenado (Demito \& Afonso, 2009). Segundo Delouche (2002) e Baudet (2003) o armazenamento de sementes em condições controladas de temperatura e umidade relativa do ar permite conservá-las por longos períodos de tempo.

Forti et al. (2010) observaram, através de testes de germinação e vigor, que o ambiente de armazenamento não controlado ocasionou maior redução do potencial fisiológico nas sementes de soja em comparação com a câmara seca (50\% UR e $\left.20^{\circ} \mathrm{C}\right)$ e com a câmara fria ( $90 \%$ UR e $\left.10^{\circ} \mathrm{C}\right)$.

Em trabalho conduzido por Maia et al. (2011) a fim de obter informações sobre a variabilidade genética associada à germinação e a emergência entre linhagens de feijão branco, os autores constataram que o poder germinativo e a velocidade de emergência diminuíram com o tempo de armazenamento em ambientes com temperatura e umidade não controladas.
Santos et al. (2005) obtiveram resultado similar; no entanto, verificaram que as cultivares de feijoeiro apresentam aptidões diferenciadas para a manutenção da qualidade fisiológica durante o armazenamento em virtude das suas características genéticas.

Desta forma, informações a respeito do comportamento das sementes frente às diversas condições que ocorrem durante este período podem auxiliar na tomada de decisão sobre o armazenamento adequado, em função da sua finalidade. $\mathrm{O}$ trabalho avaliou-se a qualidade fisiológica de lotes de sementes de cultivares de feijão carioca ao longo do armazenamento em diferentes ambientes.

\section{Material e Métodos}

O ensaio foi desenvolvido no laboratório de análise de sementes pertencente ao Departamento de Agronomia da Universidade Estadual de Londrina - UEL, Londrina, Paraná, Brasil.

O delineamento experimental utilizado foi inteiramente casualizado, em esquema fatorial $3 \times 2 \times 4$, com quatro repetições. Os fatores foram constituídos por três lotes de cultivares de feijão carioca (Lote 1: Carioca Precoce, Lote 2: IAC Carioca Tibatã e Lote 3: IAC Carioca), dois ambientes de armazenamento (ambiente natural e câmara seca) e quatro épocas de avaliação durante o armazenamento $(0,6,12$ e 18 meses).

As sementes utilizadas foram produzidas durante a safra das águas, na Fazenda Experimental Lageado, pertencente à UNESP Botucatu, que se encontra a $22^{\circ} 45^{\prime}$ latitude sul, $48^{\circ}$ 34 ' longitude oeste de Greenwich, com altitude de $750 \mathrm{~m}$. O clima da região, segundo a classificação de Köppen, é do tipo mesotérmico, Cfa, ou seja, subtropical úmido com estiagem no período de inverno. As precipitações pluviais se concentram nos meses de novembro a abril e a precipitação pluvial média anual do município é de $1433 \mathrm{~mm}$. A umidade relativa do ar é de $71 \%$, com temperatura média de $23^{\circ} \mathrm{C}$.

Os tratos culturais foram realizados de acordo com a recomendação para a cultura do feijoeiro. A colheita para cada cultivar foi realizada mecanicamente no estádio de maturação de colheita; em seguida, as sementes de cada lote foram homogeneizadas e colocadas em sacos de papel multifoliado e armazenadas em dois ambientes em ambiente natural, com temperatura e umidade não controladas e em câmara seca a temperatura de $20{ }^{\circ} \mathrm{C}$ e umidade relativa do ar de $30 \%$.

Para a determinação dos parâmetros de qualidade fisiológica nos diferentes períodos de armazenamento foram realizadas as seguintes avaliações:

Teor de água: determinado em estufa regulada a $105 \pm 3{ }^{\circ} \mathrm{C}$, durante $24 \mathrm{~h}$, conforme as Regras para Análise de Sementes (Brasil, 2009).

Primeira contagem do teste de germinação: consistiu no cálculo, em porcentagem, das plântulas normais aos cinco dias após a instalação do teste de germinação.

Germinação: foram utilizadas duas subamostras de 50 sementes por repetição totalizando 400 sementes por tratamento. As sementes foram dispostas em rolos de papel toalha, umedecidos, na proporção de 2,5 vezes a massa 
do papel seco em água. Após a semeadura os rolos foram levados a um germinador tipo câmara de crescimento sob temperatura de $25^{\circ} \mathrm{C}$. As avaliações foram realizadas aos cinco e nove dias de acordo com as Regras para Análise de Sementes (Brasil, 2009), computando-se as plântulas consideradas normais.

Envelhecimento acelerado: o teste foi conduzido em caixas plásticas (tipo gerbox) com telado contendo $40 \mathrm{~mL}$ de água ao fundo. Duas subamostras de 65 sementes por repetição foram dispostas em uma camada uniforme sobre a superfície da tela interna e após levadas a uma incubadora mantida a $42{ }^{\circ} \mathrm{C}$, por $72 \mathrm{~h}$ (Krzyzanowski et al., 1999). Após este período duas subamostras 15 sementes por repetição foram submetidas à determinação do teor de água e duas subamostras de 50 sementes por repetição foram submetidas ao teste de germinação totalizando 400 sementes por tratamento. A avaliação foi realizada aos cinco dias após a instalação do teste e os resultados foram expressos em porcentagem de plântulas normais.

Condutividade elétrica: o método utilizado foi o de condutividade de massa com duas subamostras de 50 sementes por repetição totalizando 400 sementes por tratamento. Após a obtenção da massa de cada amostra em balança digital com precisão de $0,01 \mathrm{~g}$, as sementes foram colocadas em copos plásticos contendo $75 \mathrm{~mL}$ de água deionizada e a seguir levadas a uma câmara de germinação sob temperatura constante de $25^{\circ} \mathrm{C}$, durante $24 \mathrm{~h}$ (Krzyzanowski et al., 1999). Ao final deste período foi determinada a condutividade elétrica da solução de embebicão das sementes mediante o uso de um condutivímetro de bancada digital, modelo DM-32 . Os resultados foram expressos em $\mu \mathrm{S} \mathrm{cm}^{-1} \mathrm{~g}^{-1}$ de sementes.

Emergência de plântulas em campo: realizada com quatro repetições de 100 sementes distribuídas em sulco com 2,5 m de comprimento e aproximadamente $2 \mathrm{~cm}$ de profundidade simulando a semeadura no campo sendo irrigadas sempre que necessário. A contagem das plântulas normais emergidas foi efetuada aos 14 dias após a semeadura com expressão dos resultados em porcentagem.

Os dados obtidos foram submetidos ao teste de normalidade de Shapiro-Wilk que indicou a não necessidade de transformação. Foi realizada análise de variância e as médias dos lotes e ambientes foram comparadas pelo teste de Tukey a 0,05 de probabilidade. Para as épocas de armazenamento foi realizada a análise de regressão. As análises foram executadas através do programa computacional Sistema para Análise de Variância - SISVAR (Ferreira, 2011).

\section{Resultados e Discussão}

As interações e os efeitos isolados das causas de variação estudadas para as características de qualidade fisiológica estão apresentados no quadro de análise de variância (Tabela 1).

Para o teor de água das sementes houve interação entre os fatores lotes x épocas e ambientes x épocas (Tabela 1). No início do período de armazenamento (época 0 ) o lote 2 (cultivar IAC Carioca Tibatã) apresentou maiores valores, aproximadamente $4 \%$ acima das demais (Figura 1A). Aos 6 e 12 meses não houve diferença entre os lote; já ao final do período de armazenamento
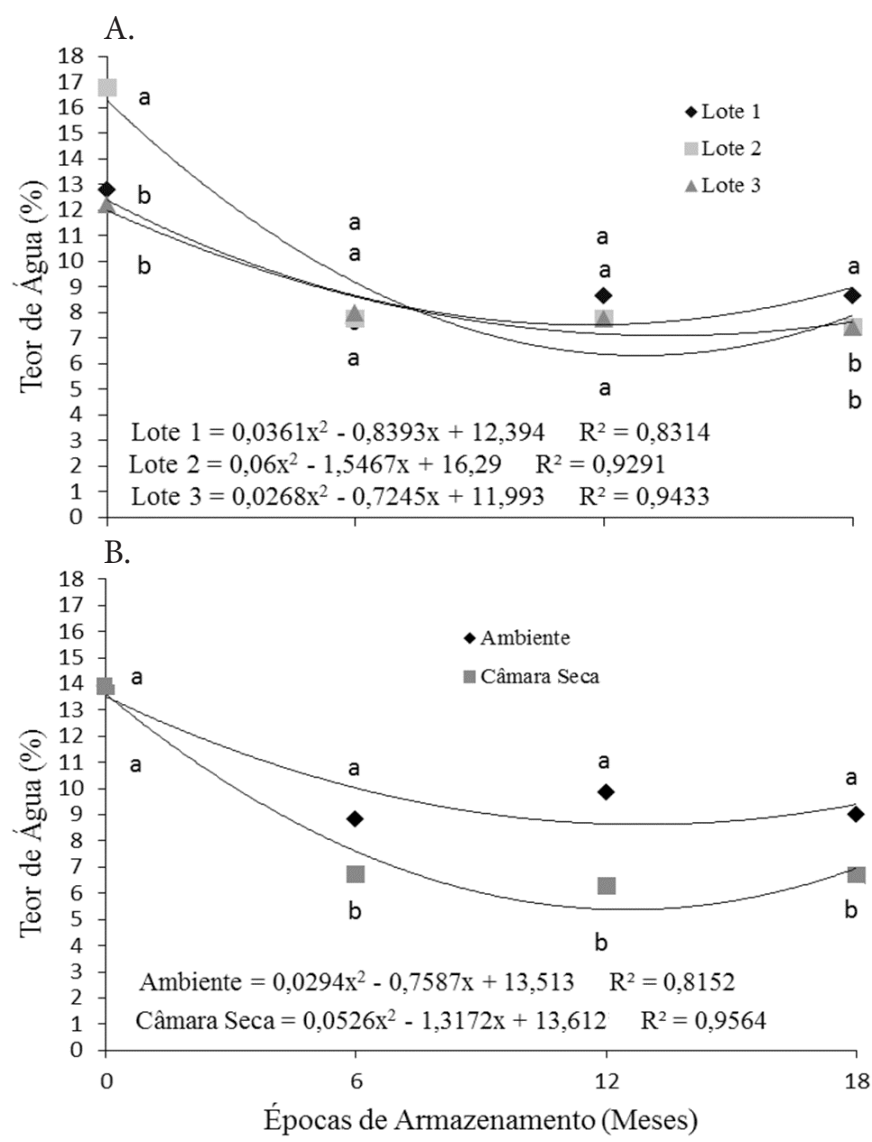

Figura 1. Teor de água em sementes de lotes de cultivares de feijão carioca (A) avaliadas ao longo do armazenamento em dois ambientes (B)

Tabela 1. Resumo de análise de variância para a qualidade fisiológica de sementes de lotes de cultivares de feijão carioca avaliadas em dois ambientes, ao longo do período de armazenamento

\begin{tabular}{|c|c|c|c|c|c|c|c|}
\hline \multirow{2}{*}{ F.V. } & \multirow{2}{*}{ GL } & \multicolumn{6}{|c|}{ Quadrados médios } \\
\hline & & $T A$ & PC & G & EA & CE & EC \\
\hline LOTES & 2 & $9,33^{*}$ & $861,79^{*}$ & $566,16^{\star *}$ & $6908,63^{*}$ & $5930,53^{*}$ & $448,63^{\star *}$ \\
\hline AMBIENTE & 1 & $96,34^{*}$ & $9,37^{\mathrm{ns}}$ & $0,16^{\text {ns }}$ & $71,76^{\text {ns }}$ & $17,11^{\mathrm{ns}}$ & $1046,76^{*}$ \\
\hline ÉPOCAS & 3 & $218,12^{*}$ & $971,15^{\star}$ & $274,94^{\text {ns }}$ & $960,76^{\star}$ & $1329,19^{*}$ & $1755,48^{*}$ \\
\hline $\mathrm{LOT}^{*} \mathrm{AMB}$ & 2 & $1,14^{\mathrm{ns}}$ & $270,37^{\mathrm{ns}}$ & $82,66^{\text {ns }}$ & $39,38^{\text {ns }}$ & $2201,07^{*}$ & $880,44^{\star}$ \\
\hline LOT*ÉPO & $\overline{6}$ & $15,41^{*}$ & $159,56^{\text {ns }}$ & $108,61^{\text {ns }}$ & $329,63^{\text {ns }}$ & $111,02^{\text {ns }}$ & $154,19^{\text {ns }}$ \\
\hline$A M B * E P O$ & 3 & $13,11^{*}$ & $1159,15^{\star}$ & $582,27^{\star}$ & $1265,37^{*}$ & $338,65^{\mathrm{ns}}$ & $677,53^{\star}$ \\
\hline LOT*AMB*EPO & 6 & $1,13^{\text {ns }}$ & $430,81^{\text {ns }}$ & $224,77^{\text {ns }}$ & $426,32^{\text {ns }}$ & $310,29^{\text {ns }}$ & $226,80^{\text {ns }}$ \\
\hline ERRO & 72 & 0,64 & 164,26 & 122,91 & 182,37 & 149,15 & 99,50 \\
\hline MÉDIA & & 9,39 & 80,52 & 86,95 & 69,38 & 72,63 & 77,63 \\
\hline CV $(\%)$ & & 8,52 & 15,92 & 12,75 & 19,46 & 16,82 & 12,85 \\
\hline
\end{tabular}

ns, não significativo, ${ }^{* *} \mathrm{e}^{*}$, significativo a 0,01 e 0,05 de probabilidade, respectivamente, pelo teste $\mathrm{F}$.

TA: teor de água; PC: primeira contagem do teste de germinação; G: germinação; EA: envelhecimento acelerado; CE: condutividade elétrica e EC: emergência de plântulas em campo 
(18 meses) o lote 1 (Carioca Precoce) apresentou maior teor de água, em média $8,62 \%$, contra $7,42 \%$ lote 2 (IAC Carioca Tibatã) e 7,43\% lote 3 (IAC Carioca). Apesar desta diferença os lotes das cultivares demonstraram comportamento similar ao longo do armazenamento apresentando teor de água abaixo de $13 \%$. Segundo Bragantini (2005) quando a umidade das sementes se mantém abaixo deste valor o processo respiratório se mantém baixo prolongando a manutenção da qualidade do produto armazenado, porém ao aumentar o teor de água o processo respiratório acelera e a deterioração se intensifica.

As sementes armazenadas em ambiente natural, com temperatura e umidade não controladas, apresentaram maior teor de água em relação às armazenadas em câmara seca (Figura 1B). Esta diferença ocorreu devido, possivelmente, ao equilíbrio higroscópico das sementes de feijão com o ambiente. Resultado similar a este foi encontrado por Smaniotto et al. (2014) em sementes de soja submetidas a dois ambientes de armazenamento.

De maneira geral, os resultados obtidos na avaliação do teor de água demonstraram a sensibilidade das sementes de feijão quanto aos ambientes e como foi possível constatar a homogeneidade da temperatura e umidade da câmara seca através da comparação dos dados com a tabela de higroscopicidade de sementes de feijão, apresentada por Resende et al. (2006).

As variações observadas no teor de água em função do tempo de armazenamento e as diferenças entre lotes e ambientes são um indicativo de possíveis alterações no comportamento do potencial fisiológico das sementes em resposta aos fatores estudados.

Os resultados da primeira contagem indicam maior vigor para as sementes do lote 1 (Carioca Precoce), por apresentarem maiores porcentagens de plântulas normais e, consequentemente, maior velocidade no processo de germinação (Tabela 2). Quanto aos efeitos de ambientes e épocas de armazenamento apresentados na Figura 2A foi observado que aos 12 e 18 meses as sementes armazenadas em câmara seca apresentavam maior vigor em relação às armazenadas em ambiente. $\mathrm{Na}$ mesma figura a curva apresentada demonstrou decréscimo no vigor das sementes de feijão ao longo do armazenamento com redução mais acentuada para o ambiente sem controle de temperatura e umidade. Resultado semelhante foi constatado por Santos et al. (2005) em quatro cultivares de feijão armazenadas em ambiente não controlado.

É importante ressaltar que o processo de deterioração das sementes armazenadas é inevitável porém, quando expostas a oscilações de temperatura e umidade, as sementes perdem o vigor mais rapidamente ficando mais suscetíveis a estresses

Tabela 2. Valores médios para os dados de primeira contagem, germinação e envelhecimento acelerado de sementes de três lotes de cultivares de feijão carioca

\begin{tabular}{lccc}
\hline \multicolumn{1}{c}{ Lotes (cultivares) } & PC & $\mathbf{G}$ & EA \\
\cline { 2 - 4 } Lote 1 (Carioca Precoce) & & $\mathbf{( \% )}$ & \\
Lote 2 (IAC Carioca Tibatã) & $77 \mathrm{a}$ & $91 \mathrm{a}$ & $80 \mathrm{a}$ \\
Lote 3 (IAC Carioca) & $78 \mathrm{~b}$ & $83 \mathrm{~b}$ & $54 \mathrm{~b}$ \\
CV (\%) & 15,92 & 12,75 & 19,46 \\
\hline
\end{tabular}

As médias seguidas da mesma letra não diferem entre si pelo teste de Tukey $(p \geq 0,05)$
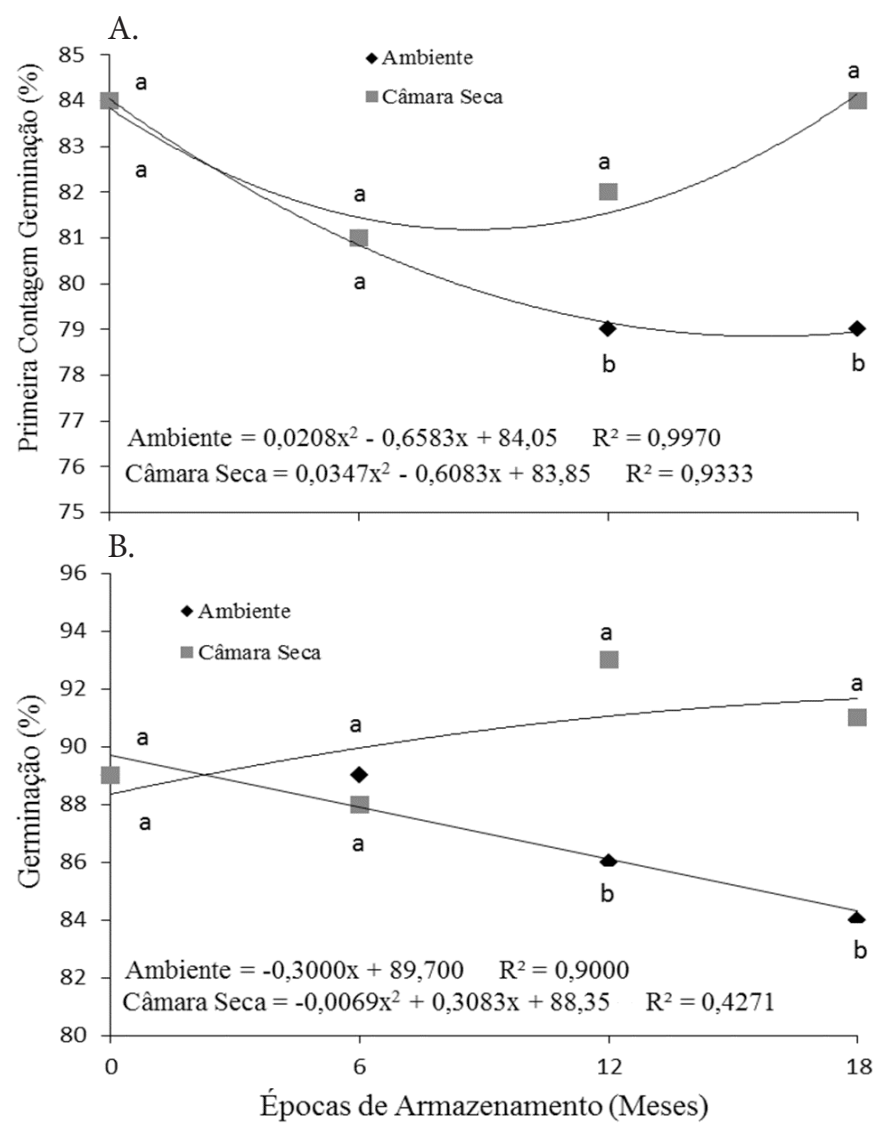

Figura 2. Primeira contagem (A) e germinação (B) de sementes de feijão carioca avaliadas ao longo do armazenamento em dois ambientes (ambiente natural e câmara seca)

durante a germinação e, eventualmente, reduzindo sua capacidade de originar plântulas normais (Silva et al., 2014).

Para os dados de germinação o lote 1 (Carioca Precoce) apresentou melhores resultados não diferindo, portanto, significativamente do lote 3 (IAC Carioca) (Tabela 2). Na interação entre ambientes e épocas de armazenamento foram constatadas diferenças aos 12 e 18 meses de armazenamento em que as sementes armazenadas em câmara seca apresentaram maior germinação (Figura 2B). Esta diferença pode ter ocorrido principalmente devido à diferença de umidade entre os ambientes. Fonseca et al. (1980) constataram que a umidade relativa é mais importante que a temperatura na manutenção da qualidade de sementes. Através da curva apresentada na Figura $2 \mathrm{~B}$ foi constatado que a germinação das sementes reduziu linearmente para o armazenamento em ambiente natural, em média $6 \%$ enquanto que, ao final da câmara seca, não houve diferença; no entanto, as sementes armazenadas em ambos os ambientes apresentaram, ao término do trabalho, porcentagens de germinação acima de $80 \%$, padrão mínimo exigido pelo ministério da agricultura para comercialização (MAPA, 2013). Com esses resultados é possível constatar a possibilidade de armazenagem de sementes de feijão carioca por longos períodos de tempo, ou seja, por mais de uma safra, independentemente do ambiente, sem que as mesmas percam sua viabilidade ou a possibilidade de comercialização. Resultados similares foram encontrados por Azeredo et al. (2005) em sementes de amendoim e Lima et al. (2014) em sementes de girassol. 
Quanto ao vigor determinado pelo teste de envelhecimento acelerado houve efeito isolado para os lotes em que o lote 1 (Carioca Precoce) e o 3 (IAC Carioca) apresentaram melhores resultados (Tabela 2). Em relação aos ambientes e épocas de armazenamento as sementes armazenadas em câmara seca demonstraram maior vigor em relação às armazenadas em ambiente com temperatura e umidade não controladas (Figura 3A). Também foi possível observar redução no vigor das sementes ao longo do período de armazenamento.

Esses resultados demonstram uma relação entre a germinação e o teste de envelhecimento acelerado sugerindo que as sementes que mantêm suas germinações depois de submetidas às condições adversas no teste de envelhecimento, também mantêm mais elevada sua germinação em condições normais de armazenamento. Segundo Marcos Filho (2005) com o passar do tempo o declínio do potencial fisiológico não se restringe somente à diminuição da capacidade de
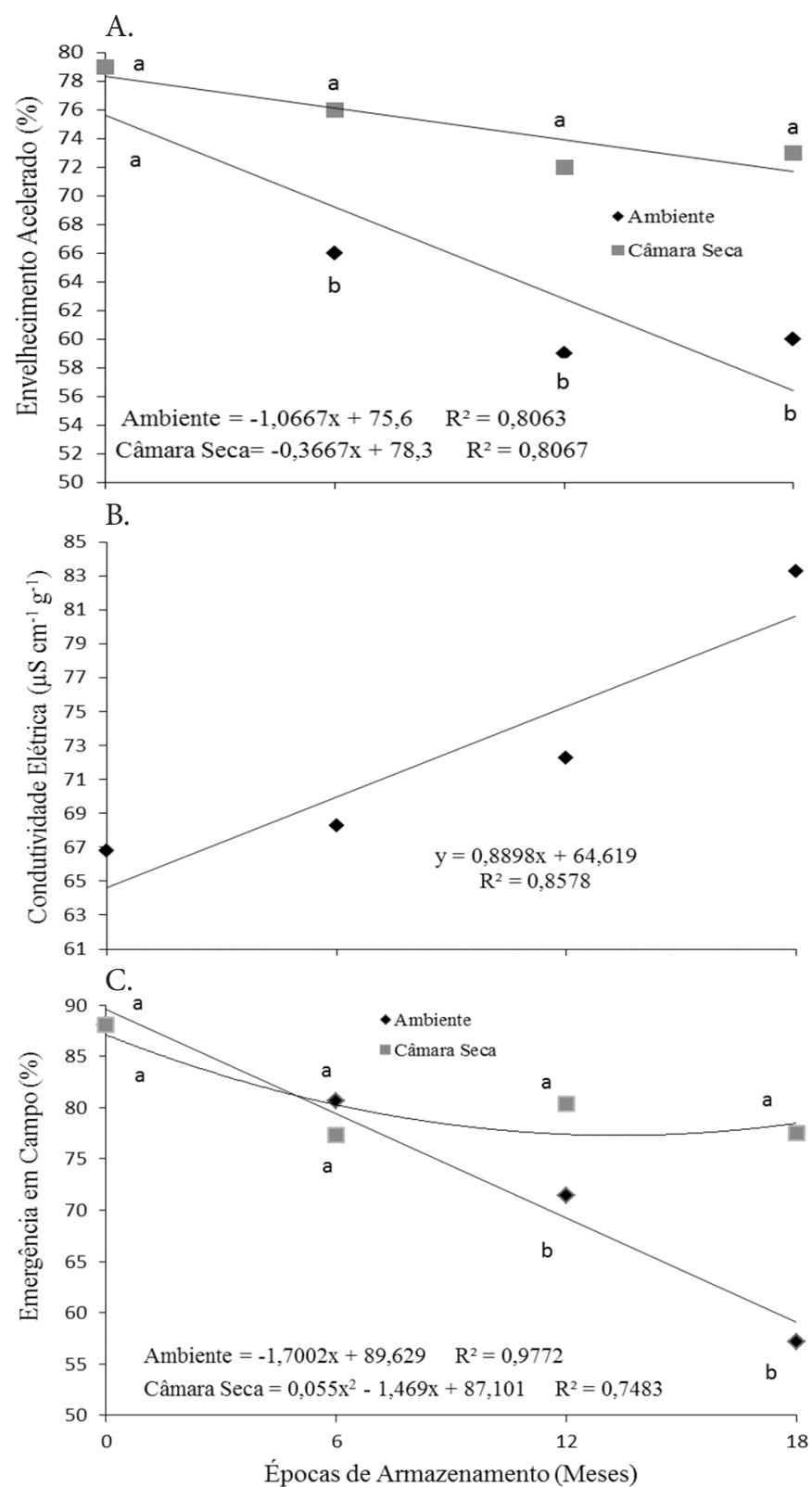

Figura 3. Envelhecimento acelerado (A), condutividade elétrica (B) e emergência de plântulas em campo (C) de sementes de feijão carioca, avaliadas ao longo do armazenamento em dois ambientes germinação, que vai ficando mais lenta, assim como se acentua a sensibilidade às adversidades ambientais caracterizando a redução do vigor das sementes. Silva et al. (2014) obtiveram conclusão parecida em trabalho com feijão comum.

O desdobramento da interação entre lotes e ambientes para os dados de vigor, avaliado pelo teste condutividade elétrica, está apresentado na Tabela 3. As sementes do lote 3 (IAC Carioca) foram as que apresentaram menores quantidades de íons lixiviados na solução, em média $58,56 \mu \mathrm{S} \mathrm{cm}^{-1} \mathrm{~g}^{-1}$ em ambiente natural e 55,90 $\mu \mathrm{S} \mathrm{cm}^{-1} \mathrm{~g}^{-1}$ em câmara seca classificando, consequentemente, as sementes como de alto vigor. $\mathrm{Na}$ comparação entre ambientes os lotes das cultivares apresentaram respostas diferenciadas. Quanto ao efeito isolado de épocas foi possível observar que, conforme se aumentou o período de armazenamento o vigor das sementes de feijão diminuiu (Figura 3B). Este resultado corrobora aos obtidos por Silva et al. (2010) e Zuchi et al. (2013) em sementes de soja. Smaniottto et al. (2014) afirmaram que este aumento da condutividade elétrica no decorrer do armazenamento pode estar relacionado ao reumedecimento das sementes que pode ter promovido uma danificação maior no sistema de membranas. Segundo Santos et al. (2005) o início do processo deteriorativo é caracterizado pela desestruturação do sistema de membranas celulares o que determina prejuízos à capacidade de retenção de solutos sendo tais danos considerados um dos primeiros eventos do processo deteriorativo das sementes.

Para a variável emergência de plântulas no campo ocorreu interação entre lotes $\mathrm{x}$ ambientes e ambientes $\mathrm{x}$ épocas de armazenamento (Tabela 1). Na comparação entre lotes houve diferença apenas para as sementes armazenadas em ambiente natural em que o lote 3 (IAC Carioca) apresentou maiores porcentagens de emergência (Tabela 3). Quando comparados os ambientes, nos lotes 1 (Carioca Precoce) e 2 (IAC Carioca Tibatã) o armazenamento em câmara seca apresentou maiores porcentagens de emergência de plântulas.

Para a interação entre ambientes e armazenamento os dados permitem constatar que aos 12 e 18 meses o armazenamento das sementes em ambiente acarretou em uma drástica redução na emergência de plântulas em relação às sementes armazenadas em câmara seca (Figura 3C). Para o efeito ao longo das épocas o aumento do período de armazenamento reduziu a emergência das plântulas no campo, para ambos os ambientes testados porém com ajuste linear e maior taxa de declínio para armazenamento em condições não controladas. Este resultado corrobora os encontrados por Santos et al. (2005) cujo período de armazenamento teve efeito deletério

Tabela 3. Valores médios de condutividade elétrica (CE) e emergência de plântulas em campo (EC) para três lotes de cultivares de feijão carioca armazenadas em dois ambientes

\begin{tabular}{|c|c|c|c|c|}
\hline \multirow[b]{2}{*}{ Lotes (cultivares) } & \multicolumn{2}{|c|}{$\operatorname{CE}\left(\mu S \mathrm{~cm}^{-1} \mathrm{q}^{-1}\right)$} & \multicolumn{2}{|c|}{ EC (\%) } \\
\hline & Ambiente & $\begin{array}{l}\text { Câmara } \\
\text { seca }\end{array}$ & Ambiente & $\begin{array}{c}\text { Câmara } \\
\text { seca }\end{array}$ \\
\hline Lote 1 (Carioca Precoce) & $74,80 \mathrm{Ba}$ & $91,37 \mathrm{Cb}$ & $72 \mathrm{Bb}$ & $81 \mathrm{Aa}$ \\
\hline Lote 2 (IAC Carioca Tibatã) & $85,79 \mathrm{Cb}$ & $69,34 \mathrm{Ba}$ & $67 \mathrm{Bb}$ & $83 \mathrm{Aa}$ \\
\hline Lote 3 (IAC Carioca) & $58,56 \mathrm{Aa}$ & $55,90 \mathrm{Aa}$ & $84 \mathrm{Aa}$ & $80 \mathrm{Aa}$ \\
\hline CV (\%) & \multicolumn{2}{|c|}{16,82} & \multicolumn{2}{|c|}{12,85} \\
\hline
\end{tabular}

As médias seguidas da mesma letra maiúscula na coluna e minúscula na linha, não diferem entre si, pelo teste de Tukey $(p \geq 0,05)$ 
nas porcentagens de emergência de plântulas de feijão em campo que constataram, no início do armazenamento, valores de emergência de 95 a 99\% e após oito meses armazenadas as sementes exibiram decréscimo de emergência com valores variando de 83 a $95 \%$.

Com base nos resultados apresentados é possível constatar que, apesar dos lotes diferirem quanto à qualidade fisiológica das sementes, devido às diferenças genéticas das cultivares, ambos apresentaram a mesma tendência de comportamento nos ambientes estudados e nas avaliações ao longo das épocas de armazenamento demonstrando que sementes de feijão carioca armazenadas em condições de ambiente não controlado apresentam redução mais acentuada na sua qualidade em detrimento aos fatores ambientais (temperatura e umidade), em relação ao armazenamento em ambiente controlado.

\section{Conclusões}

1. Sementes de feijão do lote 1 (cultivar Carioca Precoce) e lote 3 (IAC Carioca) apresentam melhor qualidade fisiológica em relação ao lote 2 (IAC Carioca Tibatã).

2. A qualidade fisiológica das sementes de feijão carioca é reduzida durante o armazenamento para todos os lotes porém com taxas mais acentuadas em condições não controladas de temperatura e umidade.

\section{Literatura Citada}

Azeredo, G. A.; Bruno, R. L. A.; Lopes, K. P.; Silva, A.; Diniz, E.; Lima, A. A. Conservação de sementes de amendoim (Arachis hypogaea L.) em função do beneficiamento, embalagem e ambiente de armazenamento. Pesquisa Agropecuária Tropical, v.35, p.37-44, 2005.

Barbosa, F. B.; Gonzaga, A. C. O. Informações técnicas para o cultivo do feijoeiro-comum na Região Central-Brasileira: 2012-2014. Goiânia: Embrapa Arroz e Feijão, 2012. 247p. Documentos 272

Baudet, L. Armazenamento de sementes. In: Peske, S. T.; Rosenthal, M. D`A.; Rota, G. R. M. Sementes: Fundamentos científicos e tecnológicos. Pelotas: UFPel, 2003. Cap.7, p.369-418.

Binotti, F. F. da S.; Haga, K. I.; Cardoso, E. D.; Alves, C. Z.; Sá, M. E.; Arf, O. Efeito do período de envelhecimento acelerado no teste de condutividade elétrica e na qualidade fisiológica de sementes de feijão. Acta Scientiarum Agronomy, v.30, p.247-254, 2008. http:// dx.doi.org/10.4025/actasciagron.v30i2.1736

Bragantini, C. Alguns aspectos do armazenamento de sementes e grãos de feijão. Santo Antônio de Goiás: Embrapa Arroz e Feijão, 2005. 28p.

Brasil. Ministério da Agricultura, Pecuária e Abastecimento. Regras para análise de sementes. Ministério da Agricultura, Pecuária e Abastecimento. Secretaria de Defesa Agropecuária. Brasília: MAPA/ACS, 2009. 395p.

Delouche, J. C. Deterioração de sementes. Seed News, v.6, p.24-31, 2002.

Demito, A.; Afonso, A. D. L. Qualidade das sementes de soja resfriadas artificialmente. Engenharia na Agricultura, v.17, p.7-14, 2009. http://dx.doi.org/10.13083/1414-3984.v17n01a01

Ferreira, D. F. Sisvar: A computer statistical analysis system. Ciência e Agrotecnologia, v.35, p.1039-1042, 2011.
Fonseca, J. R.; Freire, A. de. B.; Freire, M. S; Zimmermann F. J. P. Conservação de sementes de feijão sob três sistemas de armazenamento. Revista Brasileira de Sementes, v.2, p.19-24, 1980.

Forti, V. A.; Cicero, S. M.; Pinto, T. L. F. Avaliação da evolução de danos por "umidade" e redução do vigor em sementes de soja, cultivar TMG113-RR, durante o armazenamento, utilizando imagens de raios x e testes de potencial fisiológico. Revista Brasileira de Sementes, v.32, p.123-133, 2010. http://dx.doi.org/10.1590/S010131222010000300014

França Neto, J. B.; Krzyzanowski, F. C.; Henning, A. A. A importância do uso de sementes de soja de alta qualidade. Informativo ABRATES, v.20, p.037-038, 2010.

Goldfarb, M.; Queiroga, V. de P. Considerações sobre o armazenamento de sementes. Tecnologia e Ciência Agropecuária, v.7, p.71-74, 2013.

Grisi, P. U.; Santos, C. M. Influência do armazenamento, na germinação das sementes de girassol. Horizonte Científico, v.1, p.1-14, 2007.

Krzyzanowski, F. C.; Vieira, R. D.; França Neto, J. B. Vigor de sementes: conceitos e testes. Londrina: ABRATES, 1999. 218p.

Lima, D. C.; Dutra, A. S.; Pontes, F. M.; Bezerra, F. T. C. Storage of sunflower seeds. Revista Ciência Agronômica, v.45, p.361-369, 2014. http://dx.doi.org/10.1590/S1806-66902014000200018

Maia, L. G. S.; Silva, C. A.; Ramalho, M. A. P.; Abreu, A. de F. B. Variabilidade genética associada à germinação e vigor de sementes de linhagens de feijoeiro comum. Ciência e Agrotecnologia, v.35, p.361-367, 2011. http://dx.doi.org/10.1590/S141370542011000200018

MAPA - Ministério da Agricultura, Pecuária e Abastecimento. Instrução Normativa No 45, de 21 de setembro de 2013. Anexo XXIII - Padrões para produção e comercialização de sementes de feijão. (Phaseolus vulgaris L.). http://www.lex.com. br/legis_24861657_InstruçãoNormativa_N_45_DE_17_de setembro_de_2013.aspx. 16 Nov. 2014.

Marcos Filho, J. Fisiologia de sementes de plantas cultivadas. Piracicaba: FEALQ, 2005. 495p.

Oliveira, J. A.; Carvalho, M. L. M. de; Vieira, M. das G. G. C.; Von Pinho, E. V. R. Comportamento de sementes de milho colhidas por diferentes métodos, sob condições de armazém convencional. Ciência e Agrotecnologia, v.23, p.289-302, 1999.

Popinigis, F. Fisiologia das sementes. Ministério da Agricultura, Brasília: AGIPLAN, 1985. 289p.

Resende, O.; Corrêa, P. C.; Goneli, A. L. D.; Ribeiro D. M. Isotermas e calor isostérico de sorção do feijão. Ciência e Tecnologia dos Alimentos, v.26, p.626-631, 2006.

Santos, C. M. R.; Menezes, N. L. de; Villela, F. A. Modificações fisiológicas e bioquímicas em sementes de feijão no armazenamento. Revista Brasileira de Sementes, v.27, p.104-114, 2005. http://dx.doi. org/10.1590/S0101-31222005000100013

Silva, F. S. da; Porto, A. G.; Pascuali, L. C.; Silva, F. T. C. da. Viabilidade do armazenamento de sementes em diferentes embalagens para pequenas propriedades rurais. Revista de Ciências Agroambientais, v.8, p.45-56, 2010.

Silva, M.; Souza, H. R. T.; David, H. M. S. S.; Santos, L. M.; Silva, R. F.; Amaro, H. T. R. Qualidade fisiológica e armazenamento de sementes de feijão-comum produzidas no norte de Minas Gerais. Revista Agro Ambiente, v.8, p.97-103, 2014. 
Smaniotto, T. A. de S.; Resende, O.; Marçal, K. A. F.; Oliveira, D. E. C.; Simon, G. A. Qualidade fisiológica das sementes de soja armazenadas em diferentes condições. Revista Brasileira de Engenharia Agrícola e Ambiental, v.18, p.446-453, 2014. http:// dx.doi.org/10.1590/S1415-43662014000400013

Toledo, M. Z.; Fonseca, N. R.; Cesar, M. L.; Soratto, R. P.; Cavariani, C.; Crusciol, C. A. C. Qualidade fisiológica e armazenamento de sementes de feijão em função da aplicação tardia de nitrogênio em cobertura. Pesquisa Agropecuária Tropical, v.39, p.124-133, 2009.
Villa, L. G.; Roa, G. Secagem e armazenamento da soja industrial e sementes a granel. Campinas: Fundação Cargill, 1979. 64p.

Zuchi, J.; França Neto, J. B.; Sediyama, C. S.; Lacerda Filho, A. F.; Reis, M. S. Physiological quality of dynamically cooled and stored soybean seeds. Journal of Seed Science, v.35, p.353-360, 2013. http://dx.doi.org/10.1590/S231715372013000300012 